\title{
O conhecimento tático declarativo e processual em jogadores de futebol de diferentes escalões
}

\author{
Declarative and procedural tactical knowledge in soccer players of \\ different ages
}

\author{
D.S. Giacomini, V.O. Soares, H.F. Santos, C.J. Matias, P.J. Greco
}

RESUMO

A qualidade na prestação esportiva, nos jogos esportivos coletivos, relaciona-se com as capacidades cognitivas, especificamente com o conhecimento. Esse estudo verificou a associação entre o conhecimento tático processual convergente e divergente, assim como as associações entre o conhecimento tático processual e declarativo. Participaram do estudo 221 jogadores de futebol de campo, do sexo masculino, do escalão sub-14, sub-15 e sub-17. O conhecimento tático processual foi avaliado através da aplicação do teste KORA-OO no parâmetro "oferecer-se" e "orientar-se". O conhecimento tático declarativo foi avaliado através de cenas-situação do futebol. Os resultados indicaram uma alta associação entre o conhecimento tático processual, convergente e divergente, geral e especifico por escalão, além de uma baixa associação entre o conhecimento tático declarativo e processual (convergente e divergente). Esses dados suportam a idéia de que os conhecimentos progridem serialmente do declarativo ao processual.

Palavras-chave: conhecimento, tomada de decisão, escalões, futebol

ABSTRACT

The quality of the performance on collective games is related to cognitive capacities, specifically to knowledge. This study verified the association between convergent and divergent procedural tactical knowledge as well as the association between declarative and procedural tactical knowledge. Participated in this study 221 male soccer players of U-14, U-15 and U-17 categories. The procedural tactical knowledge was assessed by KORA-OO on the parameters "offer yourself" and "selforientation". The declarative tactical knowledge was assessed by soccer videos. Results revealed a clear association between convergent and divergent procedural tactical knowledge in general and per category and a low association between procedural (convergent and divergent) and declarative tactical knowledge. These data support the idea that knowledge progresses from declarative to procedural. Keywords: knowledge, making decision, age, soccer

Submetido: 11.12.2009 | Aceite: 29.06.2010

Diogo Schüler Giacomini, Vinícius de Oliveira Soares, Humberto Felipe Santos, Cristino Julio Matias e Pablo Juan Greco. Escola de Educação Física, Fisioterapia e Terapia Ocupacional, Universidade Federal de Minas Gerais, Brasil.

Endereço para correspondência: Diogo Schüler Giacomini, Escola de Educação Física, Fisioterapia e Terapia Ocupacional, Universidade Federal de Minas Gerais, Avenida Presidente Antônio Carlos, 6627 - Campus Pampulha (UFMG), CEP: 31310-250 Belo Horizonte - MG, Brasil.

E-mail: diogogiacomini@pop.com.br 
Os jogos esportivos coletivos (JEC) representam um sistema de ações complexas que unem funções e elementos simples das mais diversas formas, representando uma exigência nas áreas física, técnica, tática, cognitiva e motora do participante (Greco, 1995). A identidade dos jogos materializa-se na variabilidade das constelações de ataque e defesa, nas características da velocidade de jogo, na imprevisibilidade do contexto ambiental e nas riquezas das variações táticas (Tavares, Greco, \& Garganta, 2006).

Considerando a complexidade dos JEC fazse necessário interagir diferentes componentes no treino, a exemplo das capacidades cognitivas (Garganta \& Pinto, 1995; Greco \& Chagas, 1992; Tavares, 1995). O desenvolvimento das capacidades cognitivas relaciona-se com uma elevada qualidade na prestação desportiva e permite, através do conhecimento armazenado na memória, que as tomadas de decisões sejam adaptadas à situação.

O modelo pendular para a tomada de decisões baseia-se nas estruturas de recepção (percepção, antecipação e atenção) e processamento da informação (memória, pensamento e inteligência) (Giacomini, 2007; Greco, 2006; Memmert \& Perl, 2009; Morales \& Greco, 2007). Especificamente, o pensamento está relacionado com as estratégias que os atletas podem utilizar na solução dos problemas que emanam dos JEC (Greco, 2006). Quando a situação-problema demanda a execução de uma única solução correta utiliza-se o pensamento convergente, ao passo que problemas com várias soluções corretas exigem pensamento divergente (Dorsch, Häcker, \& Stapf, 2001; Greco, 2006; Guilford, 1950). Essas formas de pensamento relacionam-se entre si oferecendo subsídio uma à outra (Greco, 1999).

O conhecimento representa informações mentais em um formato específico, estruturadas ou organizadas, as quais abrangem aspectos específicos e gerais de uma determinada realidade ou fenômeno que estão armazenados nas estruturas da memória (Eysenck \& Keane, 1994; Sternberg, 2000).

Existem dois tipos de conhecimento: o conhecimento declarativo e o conhecimento processual (Anderson, 1982). Esses conhecimentos organizados e estruturados são parâmetros cognitivos que identificam um jogador de qualidade nos JEC (Rink, French, \& Granham, 1996). O conhecimento relaciona-se com o comportamento tático do jogador evitando erros ao nível de percepção e análise da situação (Konzag, 1985; Sonnenschein, 1987).

O conhecimento declarativo refere-se às estruturas de conhecimento que podem ser representadas por meio de uma rede de conceitos e suas relações, ou seja, é a capacidade de associação entre os conceitos. Portanto, saber mais significa ter uma maior rede de ligação entre os conceitos, relacionando cada elemento (Chi \& Glaser, 1980).

O conhecimento tático declarativo é verbalizado através do conhecimento das posições dos jogadores e das estratégias básicas de defesa e ataque (Thomas, French, \& Humphires, 1986). No desporto, esse conhecimento é entendido como a capacidade do atleta de saber "o que fazer" em uma determinada situação de jogo (Chi \& Glaser, 1980; Greco, 2006; Oliveira, Beltrão, \& Silva, 2003).

Por outro lado, o conhecimento tático processual é identificado nas ações que envolvem alto grau de habilidade motora podendo ser definido através do conhecimento de "como fazer as ações" (Chi \& Glaser, 1980; Eysenck \& Keane, 1994; Sternberg, 2000). Diferentemente do conhecimento tático declarativo, o processual não pode ser verbalizado, esse conhecimento é a ação motora em si, solicita o uso de processos cognitivos necessários a efetivação da mesma (Chi \& Glaser, 1980; Eysenck \& Keane, 1994; Sternberg, 2000). O conhecimento tático processual pode ser considerado, portanto, mais complexo em relação ao declarativo, pois 
inclui, além da seleção da ação, a ação propriamente dita.

Alguns excelentes executantes de habilidades técnicas no desporto podem não conseguir operacionalizar a mesma, ou seja, utilizar a técnica de uma forma eficaz em situações de jogo, pois não sabem "como", "quando" e "onde" aplicar essas técnicas, demonstrando assim uma falha no nível de conhecimento tático processual (Matias \& Greco, 2010; Turner \& Martinek, 1995).

No desporto, os anos de prática, a experiência em competições e a qualidade da prática são fatores de influência no desempenho esportivo (Campos, 1993; French \& Housner, 1994; French \& Thomas, 1987; Giacomini, 2007; Giacomini \& Greco, 2008; Matias, 2009; Thomas, 1994). Assim, a experiência é a passagem do conhecimento tático declarativo para o processual em direção ao melhor desempenho esportivo, e é denominada procedimentalização (Anderson, 1982; Dantas \& Manoel, 2005).
O objetivo do presente estudo foi verificar a associação entre conhecimento tático processual convergente e divergente por diferentes escalões. Ademais se associou o conhecimento tático declarativo ao conhecimento tático processual convergente e divergente em cada um dos escalões investigados.

\section{MÉTODO}

\section{Amostra}

A amostra voluntária deste estudo foi constituída por 221 jogadores de futebol de campo do sexo masculino: 80 do escalão sub14 (faixa etária $\leq 14$ anos), 69 do escalão sub15 (faixa etária $\leq 15$ anos) e 72 do escalão sub-17 (faixa etária $\leq 17$ anos). Todos os indivíduos da amostra eram atletas inscritos na Federação de Futebol do Estado de Minas Gerais (Brasil), participantes dos principais campeonatos estaduais e nacionais das respectivas faixas etárias.

Quadro 1

Demonstrativo das variáveis em estudo

\begin{tabular}{|c|c|c|c|c|c|}
\hline Variável & Categoria & Medidas utilizadas & Escala & \multicolumn{2}{|c|}{$\begin{array}{l}\text { Identificação para } \\
\text { análise dos dados }\end{array}$} \\
\hline CTD & $\begin{array}{l}\text { Pensamento } \\
\text { Convergente }\end{array}$ & $\begin{array}{l}\text { Teste de CTD para o futebol } \\
\text { (Adaptado de Mangas, 1999) }\end{array}$ & \multicolumn{3}{|l|}{ Intervalar } \\
\hline \multirow{10}{*}{ СТP } & \multirow{6}{*}{$\begin{array}{l}\text { Pensamento } \\
\text { Convergente }\end{array}$} & \multirow{10}{*}{$\begin{array}{l}\text { Teste KORA-OO } \\
\text { (Memmert, 2002) }\end{array}$} & \multirow{10}{*}{ Ordinal } & 1 & $\begin{array}{l}\text { Insuficiente } \\
\text { (situação fácil) }\end{array}$ \\
\hline & & & & 2 & $\begin{array}{c}\text { Insuficiente } \\
\text { (situação difícil) }\end{array}$ \\
\hline & & & & 3 & $\begin{array}{c}\text { Pobre } \\
\text { (situação fácil) }\end{array}$ \\
\hline & & & & 4 & $\begin{array}{c}\text { Pobre } \\
\text { (situação difícil) }\end{array}$ \\
\hline & & & & 5 & $\begin{array}{c}\text { Suficiente } \\
\text { (situação fácil) }\end{array}$ \\
\hline & & & & 6 & $\begin{array}{c}\text { Bom } \\
\text { (situação difícil) }\end{array}$ \\
\hline & \multirow{4}{*}{$\begin{array}{l}\text { Pensamento } \\
\text { Divergente }\end{array}$} & & & 7 & $\begin{array}{c}\text { Muito bom } \\
\text { (situação fácil) }\end{array}$ \\
\hline & & & & 8 & $\begin{array}{l}\text { Muito bom } \\
\text { (situação difícil) }\end{array}$ \\
\hline & & & & 9 & $\begin{array}{c}\text { Ótimo } \\
\text { (situação fácil) }\end{array}$ \\
\hline & & & & 10 & $\begin{array}{c}\text { Ótimo } \\
\text { (situação difícil) }\end{array}$ \\
\hline
\end{tabular}




\section{Instrumentos}

Para avaliar o conhecimento tático declarativo (CTD) dos jogadores foi utilizado o instrumento validado por Mangas (1999). O instrumento constitui-se em 11 cenas ofensivas de futebol que permitem avaliar o participante de acordo com número de respostas certas e erradas para cada situação.

O conhecimento tático processual (CTP) dos jogadores foi avaliado através da aplicação do teste KORA-OO (Avaliação Orientada através do Conceito dos Peritos) no parâmetro "oferecer-se" e "orientar-se" (Memmert, 2002).

As categorias de cada uma das variáveis, CTD e CTP, podem ser visualizadas no Quadro 1.

\section{Procedimentos}

As imagens do teste de conhecimento tático declarativo (Mangas, 1999) foram projetadas por um projetor multimídia anexado ao computador (Figura 1). As cenas-situação de jogo foram apresentadas e paralisadas durante 2 segundos no momento em que o portador da bola decidiria "o que fazer". A partir disso, surgiram na tela do computador quatro fotografias, numeradas de 1 a 4, com possíveis soluções para a jogada. $\mathrm{O}$ jogador teve o tempo que achasse necessário para decidir e anotar sua resposta na ficha de avaliação.

Para o presente estudo, foram realizadas pequenas adaptações que julgaram-se pertinentes no instrumento de Mangas (1999). Primeiramente, utilizaram-se somente as 8 cenas que obtiveram a concordância estatisticamente satisfatória por todos os peritos do teste de Mangas (1999) para, além da escolha da melhor solução, a hierarquia das 3 respostas subsequentes. Julgou-se que $\mathrm{o}$ jogador que escolhe a $2^{\text {a }}$ melhor solução para a jogada não pode ser avaliado (em quantidade de pontos) da mesma forma que o jogador que escolhe a $3^{\mathrm{a}}$ ou a pior solução, pois isto
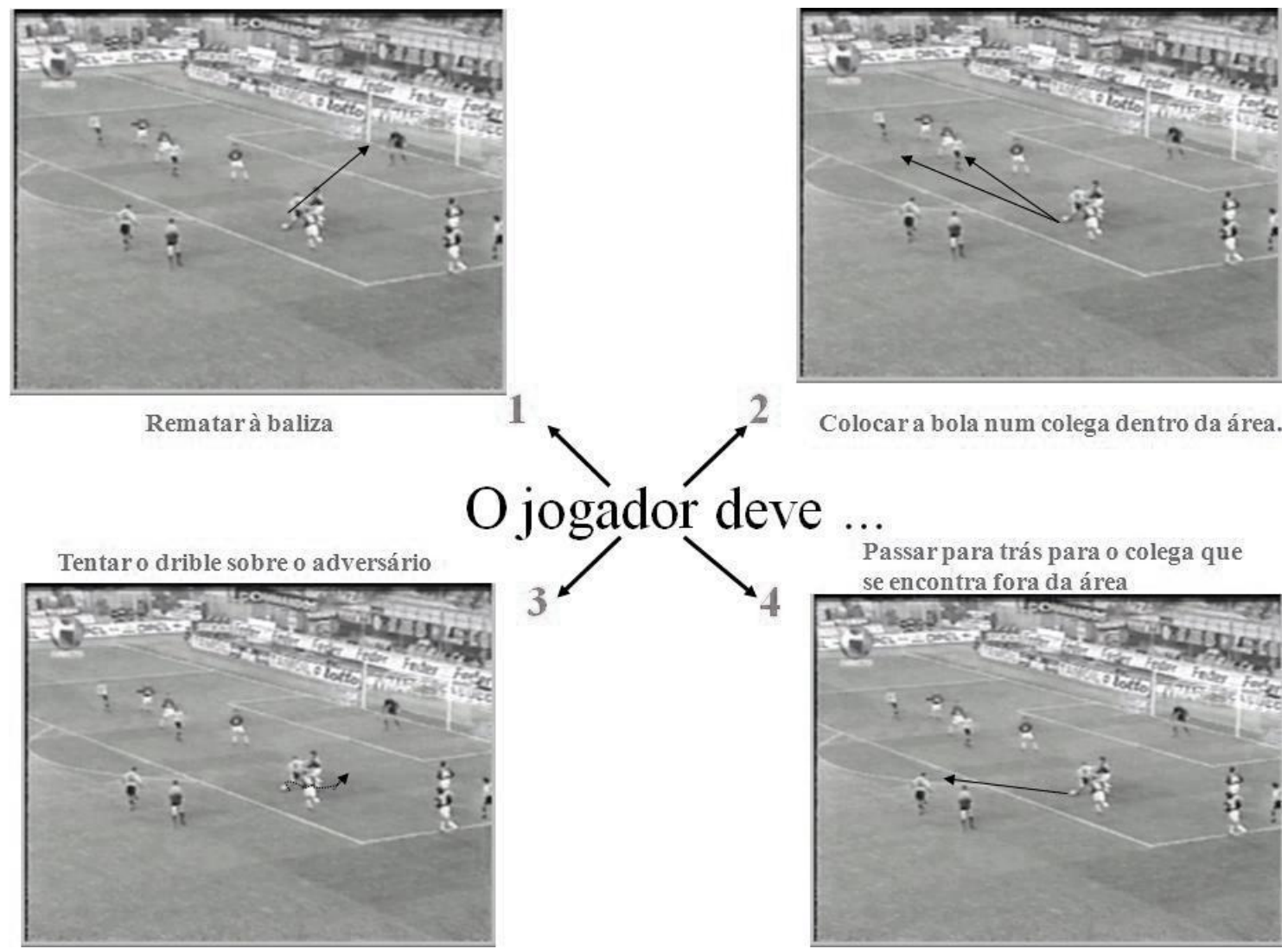

Colocar a bola num colega dentro da área. jogador deve ...

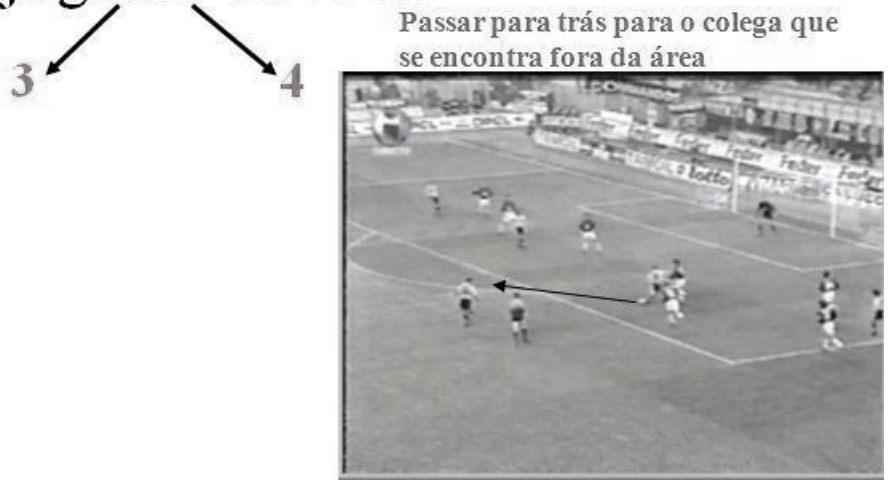

Figura 1. Exemplo de imagem no computador na aplicação do teste de CTD (Mangas, 1999) 
contradiz o princípio hierárquico do pensamento convergente, bem como a escolha da melhor a pior alternativa de decisão.

Construiu-se assim um novo gabarito para teste de conhecimento tático declarativo de Mangas (1999) com escores diferenciados para cada solução escolhida pelo avaliado, a citar:

- Melhor solução: $100 \%$ de acerto $=1.00$ ponto no escore final;

$-2^{\mathrm{a}}$ melhor solução: $75 \%$ de acerto $=.75$ pontos no escore final;

$-3^{\mathrm{a}}$ melhor solução: $50 \%$ de acerto $=.50$ pontos no escore final;

- Pior solução: $25 \%$ de acerto $=.25$ pontos no escore final.

Com essas adaptações do instrumento desenvolvido por Mangas (1999), pretendeu-se obter uma avaliação mais objetiva e fidedigna do CTD dos jogadores.

Para a aplicação do teste de CTP (KORAOO) os voluntários foram divididos em dois grupos, com três jogadores cada, identificados por coletes de duas cores diferenciadas e numerados de 1 a 6 .

O teste consiste na filmagem das ações dos atletas em um jogo de três atacantes contra três defensores num espaço quadrado de $9 \mathrm{~m}$ de lado. $O$ teste é realizado com os pés tendo o ataque o objetivo de manter a posse de bola frente aos defensores. Ao contrário, os defensores não podem desarmar o jogador em posse de bola, devendo ainda manter-se a uma distância de aproximadamente um metro do portador da bola. Podem, entretanto, antecipar posições defensivas e interceptar passes.

As 8 cenas de vídeo foram avaliadas individualmente por três peritos treinados para esse objetivo em dois momentos distintos, em análises subjacentes ao pensamento convergente e divergente das ações realizadas pelo avaliado. O critério de avaliação é a procura adequada de posições no espaço, isso significa avaliar quem não está de posse de bola.

Para obter-se a consistência interna entre os observadores desse estudo foi utilizado o coeficiente alpha de Cronbach. Para as variáveis estudadas, todos os valores foram maiores do que o valor mínimo estabelecido na literatura (alpha de Cronbach $>.70$ ), como aceitável para configurar que há consistência entre os avaliadores. Os peritos apresentaram uma consistência interna (alpha de Cronbach) de .98 indicando a fidedignidade da avaliação na aplicação do instrumento.

A pontuação do teste CTP (KORA-OO) convergente e divergente pode ser visualizada nos quadros 2 e 3 .

A coleta dos dados deu-se nas dependências dos clubes com os seus respectivos atletas, e foi condicionada ao consentimento livre esclarecido por parte dos pais ou responsáveis pelos atletas, mais os supervisores do clube e os próprios atletas.

O projeto foi aprovado pelo Comitê de Ética em Pesquisa com seres humanos da Universidade Federal de Minas Gerais (UFMG), pelo parecer n. ${ }^{\circ}$ ETIC 502/05.

\section{Análise Estatística}

Para apresentar os resultados dos diferentes escalões nos testes de conhecimento tático processual convergente e divergente e no teste de conhecimento tático declarativo utilizou-se a média, a mediana, a moda e o desvio-padrão.

A escolha da estatística apropriada para esse tipo de análise depende da escala de medida e da natureza dos dados. Considerando-se que os níveis de CTP dos testes KORA-OO (convergente e divergente) são medidos por uma escala ordinal e os níveis de CTD são medidos por uma escala intervalar, empregou-se o coeficiente de correlação Kendall's tau para a associação entre o CTP convergente e divergente. Já para associação entre o CTP convergente e divergente com o CTD utilizou-se o coeficiente de correlação de Spearman (Thomas \& Nelson, 2002).

O software utilizado para o tratamento estatístico dos dados foi o SPSS 13.0 para Windows. O nível de significância foi mantido em $p<.05$. 
Quadro 2

Oferecer-se e Orientar-se (convergente)

\begin{tabular}{|c|c|c|c|}
\hline $\begin{array}{c}\text { Qualidade da solução: } \\
\text { se oferecer se orientar, procurar } \\
\text { a posição adequada para receber } \\
\text { a bola }\end{array}$ & $\begin{array}{l}\text { Nível de } \\
\text { definição } \\
\text { da } \\
\text { situação }\end{array}$ & Pontos & Exemplo \\
\hline $\begin{array}{c}\text { Ótimo } \\
\text { Sempre Livre }\end{array}$ & Difícil & 10 & $\begin{array}{c}\text { O atleta tem, apesar de estar em uma situação } \\
\text { difícil, procurado sempre uma boa posição para dar } \\
\text { a quem tem a bola opção de passe. }\end{array}$ \\
\hline $\begin{array}{c}\text { Ótimo } \\
\text { Sempre Livre }\end{array}$ & Fácil & 9 & $\begin{array}{l}\text { O atleta tem, procurado sempre a posição ótima e } \\
\text { oferecido ao colega a possibilidade de passe. No } \\
\text { entanto, a situação não era tão difícil. }\end{array}$ \\
\hline $\begin{array}{c}\text { Muito bom } \\
\text { Quase Sempre }\end{array}$ & Difícil & 8 & $\begin{array}{l}\text { O atleta tem apesar de estar em uma situação difícil } \\
\text { procurado quase sempre achar a posição ótima para } \\
\text { que seu colega em posse de bola efetue o passe. }\end{array}$ \\
\hline $\begin{array}{c}\text { Muito bom } \\
\text { Quase Sempre }\end{array}$ & Fácil & 7 & $\begin{array}{c}\text { O atleta tem procurado quase sempre a posição } \\
\text { ótima para que o colega em posse de bola tenha a } \\
\text { opção de passe no entanto a situação não era muito } \\
\text { difícil. }\end{array}$ \\
\hline $\begin{array}{l}\text { Bom } \\
\text { Frequentemente }\end{array}$ & Difícil & 6 & $\begin{array}{l}\text { O atleta apesar de estar em uma posição difícil tem } \\
\text { procurado frequentemente uma posição ótima para } \\
\text { dar a possibilidade de passe. }\end{array}$ \\
\hline $\begin{array}{c}\text { Suficiente } \\
\text { Alternadamente }\end{array}$ & Fácil & 5 & $\begin{array}{l}\text { O atleta tem de forma irregular procurado a posição } \\
\text { ótima e oferecido ao portador da bola quase sempre } \\
\text { a possibilidade de passe. A situação não era difícil. }\end{array}$ \\
\hline $\begin{array}{c}\text { Pobre } \\
\text { Quase Nunca }\end{array}$ & Difícil & 4 & $\begin{array}{c}\text { O atleta não tem quase nunca procurado a posição } \\
\text { ótima de forma a oferecer ao portador da bola a } \\
\text { opção de passe no entanto a situação de jogo era } \\
\text { difícil. }\end{array}$ \\
\hline $\begin{array}{c}\text { Pobre } \\
\text { Quase Nunca }\end{array}$ & Fácil & 3 & $\begin{array}{c}\text { O atleta apesar de estar em uma situação fácil não } \\
\text { tem procurado quase nunca uma posição ótima para } \\
\text { oferecer ao colega portador da bola a opção de } \\
\text { passe. }\end{array}$ \\
\hline $\begin{array}{c}\text { Insuficiente } \\
\text { Nunca }\end{array}$ & Difícil & 2 & $\begin{array}{c}\text { O atleta não tem procurado quase nunca a posição } \\
\text { ótima para oferecer ao colega (portador da bola) a } \\
\text { opção de passe. No entanto, era uma situação } \\
\text { difícil. }\end{array}$ \\
\hline $\begin{array}{c}\text { Insuficiente } \\
\text { Nunca }\end{array}$ & Fácil & 1 & $\begin{array}{l}\text { O atleta apesar de estar em uma situação fácil não } \\
\text { tem procurado nunca uma ótima posição para } \\
\text { oferecer ao colega a opção de passe. }\end{array}$ \\
\hline
\end{tabular}

\section{RESULTADOS E DISCUSSÃO}

\section{Dados descritivos do conhecimento tático processual convergente e divergente e do conhecimento tático declarativo por escalão}

A Tabela 1 apresenta os dados descritivos do conhecimento tático processual convergente para os escalões estudados.

$\mathrm{Na}$ Tabela 1, verifica-se que há diferenças nas médias dos escores obtidos pelas 3 categorias em estudo, sendo a média da categoria sub-17 (6.34) a maior de todas, seguida pela média da categoria sub-15 (5.50) e da categoria sub-14 (4.08).

Tabela 1

Dados descritivos do CTP convergente por escalão

\begin{tabular}{cccccc}
\hline Escalão & $n$ & M & DP & Moda & Mediana \\
\hline Sub-14 & 80 & 4.08 & 1.04 & 4 & 4 \\
Sub-15 & 69 & 5.50 & .98 & 5 & 5 \\
Sub-17 & 72 & 6.34 & 1.17 & 6 & 6 \\
Geral & 221 & 5.26 & 1.43 & 5 & 5 \\
\hline
\end{tabular}


Quadro 3

Oferecer-se e Orientar-se (divergente)

\begin{tabular}{|c|c|c|c|}
\hline $\begin{array}{c}\text { Originalidade da } \\
\text { solução na situação } \\
\text { de jogo: uso do espaço } \\
\text { ou passe } \\
\end{array}$ & $\begin{array}{l}\text { Flexibilidade nas } \\
\text { soluções das } \\
\text { situações de jogo }\end{array}$ & Pontos & Exemplo \\
\hline $\begin{array}{l}\text { Amplo acima da média } \\
\text { (muito original) }\end{array}$ & $\begin{array}{l}\text { Duas ou mais } \\
\text { (ações originais) }\end{array}$ & 10 & $\begin{array}{l}\text { O atleta mostra diferentes soluções originais, } \\
\text { pouco comuns ou pouco conhecidas / esperadas } \\
\text { várias vezes para resolver a situação. As procuras } \\
\text { temporais de ótimas posições foram sempre } \\
\text { (completamente) excelentes. }\end{array}$ \\
\hline $\begin{array}{l}\text { Amplo acima da média } \\
\text { (original) }\end{array}$ & $\begin{array}{l}\text { Duas ou mais } \\
\text { (ações originais) }\end{array}$ & 9 & $\begin{array}{c}\text { O atleta mostra diferentes soluções originais / fora } \\
\text { do comum, ou pouco conhecidas. As procuras } \\
\text { temporais de ótimas posições foram sempre muito } \\
\text { boas. }\end{array}$ \\
\hline $\begin{array}{l}\text { Acima da média } \\
\text { (quase sempre) }\end{array}$ & $\begin{array}{l}\text { Duas ações } \\
\text { (originais, raridade } \\
\text { que não aparecem } \\
\text { de forma pouco } \\
\text { frequente) }\end{array}$ & 8 & $\begin{array}{l}\text { O atleta mostra duas diferentes soluções } \\
\text { originais / fora do comum, ou pouco conhecidas. } \\
\text { As procuras temporais de ótimas posições foram } \\
\text { sempre boas. }\end{array}$ \\
\hline $\begin{array}{l}\text { Bom, na média } \\
\text { (algumas vezes) }\end{array}$ & $\begin{array}{l}\text { Duas ações novas } \\
\text { (que aparecem de } \\
\text { forma pouco } \\
\text { frequente) }\end{array}$ & 7 & $\begin{array}{l}\text { O atleta mostra duas diferentes soluções que não } \\
\text { foram originais / fora do comum, mas que } \\
\text { aparecem de forma esporádica. As procuras } \\
\text { temporais de ótimas posições foram sempre } \\
\text { surpresas. }\end{array}$ \\
\hline $\begin{array}{l}\text { Na média } \\
\text { (ainda faz coisas novas) }\end{array}$ & $\begin{array}{c}\text { Duas ações } \\
\text { (pouco frequentes) }\end{array}$ & 6 & $\begin{array}{l}\text { O atleta mostra duas diferentes soluções que não } \\
\text { foram originais, mas que aparecem de forma } \\
\text { esporádica. As procuras temporais de ótimas } \\
\text { posições foram sempre surpresas. }\end{array}$ \\
\hline $\begin{array}{c}\text { Suficiente (ainda } \\
\text { consegue coisas novas) }\end{array}$ & $\begin{array}{l}\text { Uma } \\
\text { (ação pouco } \\
\text { frequente) }\end{array}$ & 5 & $\begin{array}{l}\text { O atleta mostra uma diferente solução que não são } \\
\text { dentro do repertório padrão, mas que já } \\
\text { apareceram. As procuras temporais de ótimas } \\
\text { posições tiveram sim novidade. }\end{array}$ \\
\hline $\begin{array}{l}\text { Pobre, próximo da } \\
\text { média } \\
\text { (com poucas coisas } \\
\text { novas) }\end{array}$ & $\begin{array}{l}\text { Uma } \\
\text { (ação pouco } \\
\text { frequente) }\end{array}$ & 4 & $\begin{array}{l}\text { O atleta mostra uma diferente solução que não são } \\
\text { dentro do repertório padrão, mas que aparecem } \\
\text { frequentemente. As procuras temporais de ótimas } \\
\text { posições tiveram sim ainda uma novidade. }\end{array}$ \\
\hline $\begin{array}{l}\text { Pobre, abaixo da média } \\
\text { (próximo do padrão) }\end{array}$ & Nenhuma & 3 & $\begin{array}{l}\text { O atleta mostra em regra gerais soluções, dentro do } \\
\text { repertório padrão, que aparecem frequentemente. } \\
\text { Ocasionalmente as procuras temporais de ótimas } \\
\text { posições tiveram um pouco de novidade. }\end{array}$ \\
\hline $\begin{array}{l}\text { Insuficiente } \\
\text { (quase somente } \\
\text { padrão) }\end{array}$ & Nenhuma & 2 & $\begin{array}{l}\text { O atleta mostra quase somente soluções dentro do } \\
\text { repertório padrão, que aparecem sempre. Muito } \\
\text { ocasionalmente as procuras temporais de ótimas } \\
\text { posições tiveram um pouco de novidade. }\end{array}$ \\
\hline $\begin{array}{l}\text { Muito Insuficiente } \\
\text { (somente padrão) }\end{array}$ & Nenhuma & 1 & $\begin{array}{l}\text { O atleta mostra somente soluções padrão, que } \\
\text { aparecem sempre. As procuras temporais de ótimas } \\
\text { posições não tiveram novidade. }\end{array}$ \\
\hline
\end{tabular}

Observando os valores da média, mediana e moda e recorrendo à escala da avaliação do teste de conhecimento tático processual (KORA-OO: convergente), pode-se descrever como caracterizam-se a maioria dos jogadores de cada categoria em relação ao CTP (convergente).

$\mathrm{Na}$ categoria sub-14 os valores de medida de tendência central apontam como característica predominante: "O jogador não 
tem quase nunca procurado a posição ótima de forma a oferecer ao portador da bola a opção de passe" (Memmert, 2002).

$\mathrm{Na}$ categoria sub-15 os valores de medida de tendência central registram o comportamento tático: "O jogador tem de forma irregular procurado a posição ótima e oferecido ao portador da bola quase sempre a possibilidade de passe" (Memmert, 2002).

Já na categoria sub-17 os valores de medida de tendência central caracterizam o comportamento tático: "O jogador apesar de estar em uma posição difícil tem procurado frequentemente uma posição ótima para dar a possibilidade de passe" (Memmert, 2002).

Foi também objetivo do estudo verificar o nível de CTP (divergente), considerando que essa forma de manifestação do pensamento é extremamente importante para o comportamento tático, na medida em que está estritamente relacionada com a criatividade tática dos atletas.

A Tabela 2 mostra os dados descritivos do CTP (divergente) dos jogadores, em função da categoria.

Tabela 2

Dados descritivos do CTP divergente por escalão

\begin{tabular}{cccccc}
\hline Escalão & $n$ & $\mathrm{M}$ & $\mathrm{DP}$ & Moda & Mediana \\
\hline Sub-14 & 80 & 2.43 & .83 & 2 & 2 \\
Sub-15 & 69 & 3.46 & .92 & 3 & 3 \\
Sub-17 & 72 & 4.18 & 1.04 & 4 & 4 \\
Geral & 221 & 3.32 & 1.18 & 3 & 3 \\
\hline
\end{tabular}

$\mathrm{Na}$ Tabela 2, verifica-se que há diferenças nas médias dos escores obtidos pelas 3 categorias em estudo, sendo a média da categoria sub-17 (4.18) a maior de todas, seguida pela média da categoria sub-15 (3.46) e da categoria sub-14 (2.43).

Observando os valores da média, mediana e moda e recorrendo à escala da avaliação do teste, pode-se descrever como caracterizam-se a maioria dos jogadores de cada categoria em relação ao CTP (divergente).

$\mathrm{Na}$ categoria sub-14 os valores de medida de tendência central apontam como característica predominante: "O jogador mostra quase somente soluções dentro do repertório padrão, que aparecem sempre. Muito ocasionalmente as procuras temporais de ótimas posições tiveram um pouco de novidade" (Memmert, 2002).

$\mathrm{Na}$ categoria sub-15 os valores de medida de tendência central registram o comportamento tático dos atletas: "O jogador mostra, em regra gerais, soluções dentro do repertório padrão, que aparecem frequentemente. Ocasionalmente as procuras temporais de ótimas posições tiveram um pouco de novidade" (Memmert, 2002).

Já na categoria sub-17 os valores de medida de tendência central levam à seguinte característica na escala: "O jogador mostra uma diferente solução que não está dentro do repertório padrão, mas que aparece frequentemente. As procuras temporais de ótimas posições tiveram sim ainda uma novidade" (Memmert, 2002).

A Tabela 3 apresenta os dados descritivos dos resultados obtidos na avaliação do CTD dos jogadores em relação à categoria.

Tabela 3

Dados descritivos do CTD por escalão

\begin{tabular}{cccccc}
\hline Escalão & $n$ & M & DP & Moda & Mediana \\
\hline Sub-14 & 80 & 6.63 & .75 & 6 & 6 \\
Sub-15 & 69 & 7.00 & .47 & 7 & 7 \\
Sub-17 & 72 & 6.97 & .60 & 6 & 6 \\
Geral & 221 & 6.85 & .65 & 6 & 6 \\
\hline
\end{tabular}

De acordo com a Tabela 3 verifica-se que há diferença de conhecimento tático declarativo entre os escalões em estudo. O sub-14 obteve uma pontuação média de 6.63. O sub-15 apresentou média de 7.00 enquanto o sub-17 alcançou média 6.97 .

\section{Associação entre os conhecimentos táticos por escalão}

A Tabela 4 apresenta os resultados do coeficiente de correlação entre o conhecimento tático processual convergente e divergente, geral e específico, para cada uma dos escalões. 
Tabela 4

Associação entre CTP Convergente e CTP Divergente por escalão

\begin{tabular}{ccc}
\hline Escalão & $n$ & Kendall's tau \\
\hline Sub-14 & 80 & $.785^{*}$ \\
Sub-15 & 69 & $.795^{*}$ \\
Sub-17 & 72 & $.805^{*}$ \\
Geral & 221 & $.865^{*}$ \\
\hline${ }^{*} p<.05$ & &
\end{tabular}

Observa-se na Tabela 4, em relação ao coeficiente de correlação geral, um alto nível de correlação entre os conhecimentos tático processual convergente e divergente (.865). Essa correlação elevada é comprovada uma vez que os escalões que obtiveram os melhores resultados no teste de conhecimento processual convergente são os mesmos que destacaram no teste de conhecimento processual divergente.

Os coeficientes de correlação entre os testes de conhecimento tático processual convergente e divergente elevaram-se do escalão mais novo (sub-14) (.785) para o mais experiente (sub17) (.805). Essa correlação mostra a importância da interação dos pensamentos convergente e divergente para resolução dos problemas apresentados no jogo.

Os resultados apresentados acima confirmam a tendência de que os jogadores que demonstram maior inteligência de jogo são também os mais criativos, corroborando a idéia apresentada no modelo pendular do conhecimento técnico-tático nos JEC em que a ação criativa é também inteligente (Giacomini, 2007; Greco, 2006; Memmert \& Perl, 2009; Morales \& Greco, 2007).

A Tabela 5 apresenta os resultados de correlação entre o conhecimento tático declarativo e processual convergente geral e especifico por escalão.

De acordo com a Tabela 5 as correlações entre o conhecimento tático declarativo e processual convergente foram negativas para todos os escalóes. Importante ressaltar que o sub-15 apresentou praticamente uma correlação negativa perfeita $(-.990)$.
Tabela 5

Associação entre CTD e CTP Convergente por escalão

\begin{tabular}{ccc}
\hline Escalão & $n$ & rho Spearman \\
\hline Sub-14 & 80 & -.160 \\
Sub-15 & 69 & -.990 \\
Sub-17 & 72 & -.560 \\
Geral & 221 & $.148^{*}$ \\
\hline${ }^{*} p<.05$ & &
\end{tabular}

A Tabela 6 apresenta os resultados de correlação entre o conhecimento tático declarativo e processual divergente geral e especifico por escalão.

Tabela 6

Associação entre CTD e CTP Divergente por escalão

\begin{tabular}{ccc}
\hline Escalão & $n$ & rho Spearman \\
\hline Sub-14 & 80 & .360 \\
Sub-15 & 69 & .104 \\
Sub-17 & 72 & -.001 \\
Geral & 221 & $.153^{*}$ \\
\hline${ }^{*} p<.05$ & &
\end{tabular}

Pela Tabela 6, o sub-14 obteve uma correlação positiva (.360), ao contrário dos demais escalões. Acrescenta-se ainda que todas as correlações foram baixas.

O resultado contradiz a alta correlação entre o conhecimento tático processual e declarativo (Blomqvist, Vänttinen, \& Luthanen, 2005; French \& Thomas, 1987; Garganta, 1997; Matias, 2009; Maxwell, Masters, \& Eves, 2003; Thomas, 1994). Entretanto, explica-se em parte os resultados a partir do exposto de que o conhecimento é aprendido e codificado de forma declarativa para então ser compilado em uma forma processual (Anderson, 1982; Campos, 1993; Giacomini, 2007; Matias, 2009; Matias \& Greco, 2010).

Ao fim dessa discussão, em consonância com os resultados apurados, verifica-se uma concordância com o estudo de Williams e Davids (1995). Em ambos o conhecimento tático declarativo demonstrou um baixo rendimento em praticantes não experientes no futebol. Sendo ainda que no estudo de Williams e Davids (1995) os praticantes não 
experientes tiveram resultados semelhantes aos expectadores desta modalidade desportiva. Por fim, o presente estudo corrobora com o trabalho de Williams e Davids (1995), pois os jogadores mais experientes demonstraram um conhecimento tático declarativo mais elaborado.

Em relação ao conhecimento tático processual, este estudo relaciona-se com a investigação científica de Kannekens, ElferinkGemser e Visscher (2009), com amostra composta por jogadores das seleções nacionais de jovens da Alemanha e da Indonésia, pois no mesmo também foi encontrado uma correlação positiva entre habilidades táticas e o nível competitivo de jogadores de futebol.

\section{CONCLUSÕES}

Em direção a verificar a associação entre o conhecimento tático processual convergente e divergente, por escalão, observou-se um alto nível de correlação entre esses conhecimentos. Por escalão os resultados foram semelhantes, tendo como característica maior correlação quanto mais elevado o escalão. Assim, expondo a importância da interação dos pensamentos convergente e divergente para resolução dos problemas apresentados no jogo. Em direção a verificar a associação entre o conhecimento tático declarativo e processual (convergente e divergente) geral e especifico por escalão, verificou-se uma baixa correlação entre esses conhecimentos. $\mathrm{O}$ processo de ensino-aprendizagem-treinamento foi capaz de propiciar aos atletas um processo de tomada de decisão inteligente e criativa, ocorrendo a procedimentalização do declarativo para o processual, diagnosticado pela investigação desse estudo. Novas pesquisas científicas devem emergir com o presente estudo para averiguar as metodologias de ensino que estão a propiciar um eficaz processo decisório por parte do atleta nos jogos esportivos coletivos.

\section{REFERÊNCIAS}

Anderson, R. J. (1982). Acquisition of cognitive skill. Psychological Review, 89, 369-406.
Blomqvist, M., Vänttinen, T., \& Luhtanen, P. (2005). Assessment of secondary school students' decision-making and game-play ability in soccer. Physical Education \& Sport Pedagogy, 10, 107-119.

Campos, W. (1993). Effects of age and skill level on motor and cognitive components of soccer performance. Tese de doutorado, University of Pittsburgh, Estados Unidos da América.

Chi, M. T., \& Glaser, R. (1980). The measurement of expertise: Analysis of the development of knowledge and skill as a basis for assessing achievement. In E. L. Baker \& E. L. Quellmalz (Eds.), Educational testing and evaluation: Design, analysis, and policy (pp. 37-48). Beverly Hills, CA: Sage Publications.

Dantas, L. E., \& Manoel, E. J. (2005). Conhecimento no desempenho de habilidades motoras: O problema do especialista motor. In G. Tani (Ed.), Comportamento motor: Aprendizagem e desenvolvimento (pp. 295-313). Rio de Janeiro: Guanabara Koogan.

Dorsch, F., Häcker, H., \& Stapf, K. H. (2001). Dicionário de Psicologia. Petrópolis: Vozes.

Eysenck, M. W., \& Keane, M. T. (1994). Psicologia cognitiva: Um manual introdutório. Porto Alegre: Artmed.

French, K., \& Housner, L. (1994). Expertise in learning, performance and instruction in sport and physical activity: Introduction. Quest, 46, 149-152.

French, K., \& Thomas, J. (1987). The relation of knowledge development to children's basketball performance. Journal of Sport Psychology, 9, 15-32.

Garganta, J. (1997). Modelação tática do jogo de futebol: Estudo da organização da fase ofensiva em equipas de alto rendimento. Tese de Doutorado, Universidade do Porto, Portugal.

Garganta, J., \& Pinto, J. (1995). O ensino de futebol. In A. Graça \& J. Oliveira (Eds.), O ensino dos jogos desportivos (pp. 95-137). Porto: CEJD-UP.

Giacomini, D. S. (2007). Conhecimento tático declarativo e processual no futebol: Estudo comparativo entre jogadores de diferentes categorias e posições. Dissertação de Mestrado, Universidade Federal de Minas Gerais, Brasil.

Giacomini, D. S., \& Greco, P. J. (2008). Comparação do conhecimento tático processual em jogadores de futebol de diferentes categorias e posições. Revista Portuguesa de Ciências do Desporto, 8(1), 126-136. 
Greco, P. J. (1995). O ensino do comportamento tático nos jogos esportivos coletivos: Aplicação no handebol. Tese de Doutorado, Universidade Estadual de Campinas, Brasil.

Greco, P. J. (1999). Cognição e ação. In D. Samulski (Ed.), Novos conceitos em treinamento esportivo (pp. 119-153). Minas Gerais: CENESP-UFMG.

Greco, P. J. (2006). Conhecimento tático-técnico: Eixo pendular da ação tática (criativa) nos jogos esportivos coletivos. Revista Brasileira de Educação Física e Esporte, 20, 210-212.

Greco, P. J., \& Chagas, M. H. (1992). Considerações teóricas da tática nos jogos desportivos coletivos. Revista Paulista de Educação Física, 6, 47-58.

Guilford, J. P. (1950). Creativity. American Psychologist, 5, 444-454.

Kannekens, R., Elferink-Gemser, M. T., \& Visscher, C. (2009). Tactical skills of world-class youth soccer teams. Journal of Sports Sciences, 27, 807812.

Konzag, I. (1985). A formação técnico-tática nos jogos desportivos. Futebol em Revista, 14, 41-45.

Mangas, C. J. (1999). Conhecimento declarativo no futebol: Estudo comparativo em praticantes federados e não-federados, do escalão de Sub-14. Dissertação de Mestrado, Universidade do Porto, Portugal.

Matias, C. J. A. (2009). O conhecimento tático declarativo e a distribuição de jogo do levantador de voleibol: Da formação ao alto nível. Dissertação de Mestrado, Universidade Federal de Minas Gerais, Brasil.

Matias, C. J. A., \& Greco, P. J. (2010). Cognição e ação nos jogos esportivos coletivos. Ciências \& Cognição, 15, 252-271.

Maxwell, J. P., Masters, R. S. W., \& Eves, F. F. (2003). The role of working memory in motor learning and performance. Consciousness and Cognition, 12, 376-402.

Memmert, D. (2002). Diagnostik taktischer leistungskompnenten: Spieltestsituationen und konzeptorientierte expertenratings. Tese de Doutorado, Universidade de Heidelberg, Alemanha.

Memmert, D., \& Perl, J. (2009). Analysis and simulation of creativity learning by means of artificial neural networks. Human Movement Science, 28, 263-282.
Morales, J. P., \& Greco, P. J. (2007). A influência de diferentes metodologias de ensinoaprendizagem-treinamento no basquetebol sobre o nível de conhecimento tático processual. Revista Brasileira de Educação Física, 21, 291-299.

Oliveira, F. A., Beltrão, F. B., \& Silva, V. F. (2003). Metacognição e hemisfericidade em jovens atletas: Direcionamento para uma pedagogia de ensino desportivo. Revista Paulista de Educação Física, 17, 5-15.

Rink, J., French, K., \& Graham, K. (1996). Implications for practice and research. Journal of Teaching in Physical Education, 15, 490-509.

Sonnenschein, I. (1987). Psychologisches training im leistungssport. In H. Gabler, J. R. Nitsch, \& R. Singer (Eds.), Einfuhrung in die sportpsychologie - Teil 2: Anwendungsfelder (pp. 159-188). Schorndorf: Hofmann.

Sternberg, R. J. (2000). Psicologia cognitiva. Porto Alegre: Artmed.

Tavares, F. (1995). O processamento da informação nos jogos desportivos. In A. Graça \& J. Oliveira (Eds.), O ensino dos jogos desportivos (pp. 35-46). Porto: CEJD/FCDEF-UP.

Tavares, F., Greco, P., \& Garganta, J. (2006). Perceber, conhecer, decidir e agir nos jogos desportivos coletivos. In G. Tani, J. O. Bento, \& R. D. S. Petersen (Eds.), Pedagogia do desporto (pp. 284-298). Rio de Janeiro: Guanabara Koogan.

Thomas, J. R., \& Nelson, J. K. (2002). Métodos de pesquisa em atividade física. Porto Alegre: Artmed.

Thomas, J., French, K., \& Humphires, C. (1986). Knowledge development and sport skills performance: Directions for motor behavior research. Journal of Sport Psychology, 8, 259-272.

Thomas, K. (1994). The development of sport expertise: From Leeds to MVP legend. Quest, 46, 199-210.

Turner, A., \& Martinek, T. (1995). Teaching for understanding: A model for improving decision making during game play. Quest, 44, 44-63.

Williams, A. M., \& Davids, K. (1995). Declarative knowledge in sport: A by-product of experience or a characteristic of expertise. Journal of Sport and Exercise Psychology, 17, 258-275.

(c)) EY-Nc Todo o conteúdo da revista Motricidade está licenciado sob a Creative Commons, excepto quando especificado em contrário e nos conteúdos retirados de outras fontes bibliográficas. 